\section{Vital Statistics of Scotland}

AcCoRDING to the quarterly return of the RegistrarGeneral of Scotland, 1942 was a very healthy year, as is shown by the fact that the death-rate from all causes was 13.0 per 1,000 of the population, or 1.5 below the corresponding rate for 1941 and 0.7 below the average for the quinquennium 1936-41. The birth-rate was 18.1 per 1,000 , or 0.2 above the average for 1941 and 0.5 above the five-year period. Both infantile mortality and maternal mortality showed very satisfactory rates, the former being 69 per 1,000 live births and the latter 4.0 per 1,000 total births, which was the lowest rate on record for about four decades. The deaths from the principal epidemic diseases were the lowest on record, amounting to 1,060 . As regards the chief chronic diseases with a high mortality, the death-rate from all forms of tuberculosis was 80 per 100,000 . Though there was a decline in non-respiratory tuberculosis, especially in the age-group fifteen to twenty-five, there was a definite rise in the respiratory tuberculosis death-rate. Increase in the death-rate for syphilis was shown mainly by an increase in aneurysm and congenital syphilis. The death-rate from malignant disease was 171 per 100,000 , which represented an increase above the 1941 rate. On the other hand, there was a definite decline in the death-rate for cardiac and respiratory diseases apart from tuberculosis and malignant disease.

\section{Syphilis in the United States}

IN a recent paper ( $J$. Amer. Med. Assoc., 122, 365 ; 1943) Dr. W. G. Smillie maintains that the incidence of syphilis among white men in the greater part of the United States is low, and that it is limited for the most part to the lowest classes of society, so that it has become a disease largely of the ignorant, the careless, the criminal and the social outcast. Syphilis, however, is more than ten times as prevalent among the Negroes as among white persons. In recent examinations for army service, the incidence of syphilis among whites was $0 \cdot 2$ per cent, as compared with $11 \cdot 2$ per cent among Negroes.

\section{Tuberculosis in Buenos Aires}

According to Dr. Alejandro A. Raimondi ( $J$. Amer. Med. Assoc., 208, 121; 1943), director of the Municipal Centre of Buenos Aires for a Campaign against Tuberculosis, there were 2,708 deaths from that disease in Buenos Aires in 1941. The increase in the disease is due to the influx of tuberculous subjects from the provinces. The routine practice of taking skiagrams of children has resulted in finding tuberculosis where it was not suspected and also in preventing the spread of the disease. X-ray examination of the chest of apparently normal persons has yielded good results. Tuberculosis has been found in only five cases $(1 \cdot 3$ per cent) in a group of 384 students and in only twenty-five cases ( 3.02 per cent) in 826 applicants for municipal posts.

\section{Agricultural Research Council Appointments}

The Committee of the Privy Council for Agricuitural Research has appointed the Right Hon. the Earl De La Warr to be chairman of the Agricultural Research Council in succession to the late Sir Thomas Middleton. The Committee has further appointed Prof. I. de Burgh Daly to be a member of the
Agricultural Research Council in succession to Sir Joseph Barcroft, whose term of office as a member has expired.

\section{Library Stocks of Periodicals}

REFERRING to the letter on "Library Stocks of Periodicals" published in Nature of July 24, Mr. C. C. Barnard writes: "I inadvertently failed to appreciate the proposals of a committee of the Association of Special Libraries and Information Bureaux, which has under consideration the preparation of a Union Catalogue of Periodicals in British Libraries. This Committee proposes at present to limit its plan to the compilation of a consolidated check list composed of entries in the 'World List of Scientific Periodicals', the 'Union Catalogue of Periodical Publications in University Libraries', and the relevant section of the 'British Museum Catalogue'. The work which it contemplates should be of assistance in the accomplishment of the larger scheme which I outlined."

\section{Wellcome Junior Fellowship}

The Joint Advisory Committee of the Wellcome Foundation and the Veterinary Educational Trust has awarded the first Wellcome Junior Fellowship to Mr. John Lochiel McGirr. The fellowship is tenable for one year at $£ 400$ per annum and is subject to renewal for a further period of one or two years at the discretion of the Advisory Committee. Another fellowship of equal value will be awarded in April 1944. The award to Mr. McGirr represents the first result of the recent foundation of the Veterinary Educational Trust.

\section{The Night Sky in September}

Futl moon occurs on September 14d. 03h. 40m. U.T. and new moon on September 29d. 11h. $29 \mathrm{~m}$. The following conjunctions with the moon take place: Sept. 2d. 00h., Mercury $7^{\circ}$ S.; Sept. 20d. 03h., Mars $4^{\circ}$ N.; Sept. 21d. 05h., Saturn $3^{\circ}$ N. ; Sept. 25d. 14h., Jupiter $0.3^{\circ}$ N. ; Sept. 26d. 16h., Venus $8^{\circ} \mathrm{S}$. The following occultations of stars brighter than magnitude 6 take place : Sept. 8 d. 2lh. $02.4 \mathrm{~m} ., 15 \mathrm{Sgr}(D)$; Sept. 10d. 21h. 27.3m., $\sigma$ Cap $(D)$; Sept. 26d. 11h. $08.2 \mathrm{~m}$., $\alpha$ Leo $(D)$; Sept. 26d. 12h. 12.1m., $\alpha$ Leo $(R)$. The times are given for Greenwich and $D$ and $R$ refer to disappearance and reappearance respectively. Mercury, an evening star at the beginning of the month, sets a quarter of an hour after the sun on Sept. 1. The planet is approaching the sun and is in inferior conjunction on Sept. 24. venus is in inferior conjunction with the sun on Sept. 6. At the middle and end of the month the planet can be seen as a morning star, rising at $4 \mathrm{~h} .43 \mathrm{~m}$. and $3 \mathrm{~h} .20 \mathrm{~m}$. respectively. Mars, in the constellation of Taurus, is an evening star and sets at $13 \mathrm{~h} .20 \mathrm{~m}$., $13 \mathrm{~h}$. and $12 \mathrm{~h}$. $32 \mathrm{~m}$. at the beginning, middle and end of the month respectively. Jupiter is a morning star, rising at $3 \mathrm{~h}$. at the beginning and $1 \mathrm{~h} .33 \mathrm{~m}$. at the end of the month. Saturn, in the constellation of Taurus, is a morning star, rising at $22 \mathrm{~h}$. $08 \mathrm{~m}$. in the middle of the month. Times are given approximately for the latitude of Greenwich. The Autumn Equinox commences on Sept. $23 \mathrm{~d}$. $22 \mathrm{~h}$. The longer evenings provide opportunities for those who are interested in observational work, and many interesting objects are within the range of a small telescope. 